doi.org/ 10.51891/rease.v7i12.3567

\title{
CONTRIBUIÇÕES DA CLÍNICA PSICANALÍTICA LACANIANA PARA O TRATAMENTO DA PSICOSE INFANTIL
}

\author{
Bianca Lopes Oleiro ${ }^{1}$ \\ Rafael da Nova Favarin ${ }^{2}$
}

\begin{abstract}
RESUMO: Esta pesquisa teve como objetivo investigar as contribuições da clínica psicanalítica lacaniana para o tratamento da psicose infantil, sob a perspectiva do diagnóstico diferencial entre psicose infantil e autismo e, como consequência, a necessidade de tratamentos específicos a cada um destes casos. Outro aspecto de análise foi a investigação quanto à expansão imprescindível do repertório de estudos e bibliografias sobre o tema, a fim de aprimorar a construção de métodos e tratamentos característicos a cada caso, sendo o intuito garantir a eficácia dos tratamentos. Para isso, a realização do trabalho teve como método empregado o levantamento bibliográfico e a revisão dos materiais selecionados, a partir do referencial teórico da Psicanálise. No primeiro capítulo foi possível aprofundar tal análise ao descrever os conceitos da psicose. Já no segundo capítulo, especificou-se acerca das contribuições clássicas da psicanálise para a clínica infantil, bem como em relação aos manejos clínicos específicos para o tratamento da psicose infantil. Os resultados da pesquisa apontam que o objetivo da psicanálise de orientação lacaniana no tratamento da psicose infantil é compreender a demanda da própria criança em sofrimento, e auxiliá-la em seu desenvolvimento e qualidade de vida. Evidencia-se que há eficácia nesse tratamento, à luz da psicanálise, com base nas experiências de transformação do método clássico desenvolvidas também por psicanalistas contemporâneos, para alcançar o discurso analítico da criança psicótica.
\end{abstract}

Palavras-chave: Psicose Infantil. Autismo. Psicanálise. Clínica. Lacan.

ABSTRACT: This research aimed to investigate the contributions of the Lacan's psychoanalytic clinic for the treatment of cases of child psychosis, from the perspective of the differential diagnosis between child psychosis and autism and as a consequence the need for specific treatments for each of these cases. Another aspect of analysis was the investigation of the essential expansion of the repertoire of studies and bibliographies on the subject in order to improve the construction of methods and treatments characteristic to each case, with the purpose of ensure effectiveness of these treatments. For this purpose, the method used to carry out the work was a bibliographic survey and a review of selected materials, based on the theoretical framework of Psychoanalysis. In the first chapter, it was possible to deepen this analysis by describing the concepts of psychosis. In the second chapter, it was specified about the classic contributions of psychoanalysis to the clinical child, as well as in relation to specific clinical managements for the treatment of child psychosis. The research results indicate that the objective of Lacanian oriented psychoanalysis in the treatment of child psychosis is to understand of the suffering child's own demands, and to help them in their development and quality of life. It is evident that this treatment is effective, in the light of psychoanalysis, based on the experiences of transformation of the classical method, also developed by contemporary psychoanalysts, to reach the psychotic child's analytical discourse.

Keywords: Child Psychosis. Autism. Psychoanalysis. Clinic. Lacan.

IB acharel em Psicologia pelo Centro Universitário UNIFAAT. E-mail: bianca.oleiro@hotmail.com ${ }^{2}$ Mestre em Psicologia; professor nos cursos de Psicologia e Pedagogia no Centro Universitário Unifaat. Email:rnfavarin@gmail.com 


\section{INTRODUÇÃO}

No que se refere à análise das etiologias das psicopatologias, de acordo com a psicanálise, é imprescindível considerar tanto o fator de constituição do ser humano, quanto o fator ambiental, sendo assim, “[...] o psicanalista não descarta a hipótese biológica, mas recusa a discussão posta em termos de uma dicotomia biológico/psíquico. A origem não está nem em um, nem em outro domínio" (KUPFER, 1999b, p. 97). De acordo com a visão psicanalítica, pois, a origem de uma psicopatologia refere-se à conjunção do psíquico e do somático, de modo que não há como aferir o grau de influência de cada um deles. É por este motivo que, segundo Kupfer (1999b, p. 98) "a psicanálise tem demarcado claramente a irredutibilidade do discurso médico ao discurso psicanalítico".

O que se sabe, sobretudo, é que o bebê deixa de ser apenas um organismo e desenvolve-se como ser humano, se houver, necessariamente, outro humano, já que depende da demanda do outro "que sustente o lugar de Outro Primordial e que o pilote em direção ao mundo humano, que lhe dirija os atos para além dos reflexos, e principalmente, que lhes dê sentido" (KUPFER, 1999b, p. 99). A partir desta perspectiva, entende-se que uma criança com complicações neurológicas pode ter obstáculos para receber o sustento do outro e desenvolver-se como ser humano, todavia, uma criança saudável do ponto de vista biológico, mas não saudável no aspecto psíquico, também pode ter dificuldades caso não haja um outro que "o introduza na ordem simbólica” (KUPFER, 1999b, p. 99).

A prática da clínica psicanalítica demonstra que psicose e autismo são transtornos diferentes (KLINGER; REIS; SOUZA, 20II). Assim, a fim de buscar tratamentos eficientes e possibilitar maior quantidade de estudos quanto às divergências, a psicanálise possui diagnóstico diferencial para psicose infantil e para o autismo; todavia, ainda não há definição precisa quanto tais divergências. Neste sentido, compreende-se que os psicanalistas contemporâneos têm dedicado seus estudos em busca da definição de quadros distintos para autismo e psicose, com o objetivo de compreender as divergências nas manifestações dos sintomas, além de delimitar a estrutura clínica para ambos os tratamentos (KUPFER, 1999b).

Em relação ao termo psicose infantil, sabe-se que ele não é mais utilizado nos manuais diagnósticos de doenças da psiquiatria. Quando a psicose infantil, foi integrada aos Transtornos Globais do Desenvolvimento (TGD), estes também incluíam o Autismo, dentre outros transtornos. Todavia, o termo autismo infantil foi adotado e descrito, pela 
primeira vez, na terceira edição do Manual de Diagnóstico dos Transtornos Mentais (DSM - III) (PAULA et al., 2017 apud CORREIO et al., 202I).

Nota-se que a classificação Internacional de Doenças (CID), até sua versão ıo, englobava o autismo aos Transtornos Globais do Desenvolvimento, além de classificá-lo em oito diferentes categorias com base na variabilidade significativa em termos de sintomas e gravidade. Os sintomas baseiam-se na tríade do autismo: prejuízos em comum na comunicação social, interação social e no comportamento. Após diversas mudanças de nomenclatura, a versão do DSM - V passa a reconhecer o transtorno como Transtorno do Espectro do Autismo - TEA. Esta modificação explica-se pela necessidade de especificar o TEA, já que este possui variados sintomas e graus. Sabe-se, ainda, que o autismo é considerado, atualmente, como sendo "um transtorno do neurodesenvolvimento caracterizado por dificuldades evidentes na comunicação e na interação social, em contextos diferenciados e de forma permanente" (CORREIO et al., 202I, p. 22562).

Inicialmente esta pesquisa buscou descrever os conceitos de psicose. Sabe-se que esta, para a psicanálise lacaniana, apresenta divergências evidentes entre as patologias psicose infantil e autismo, no entanto, ainda não há, no campo médico, uma diferenciação definida quanto a isto. Todavia, embora ainda não haja tal definição precisa, a hipótese de tal corrente teórica refere-se ao fato de que "o autista está fora do campo da linguagem, enquanto o psicótico está na linguagem, mas fora do discurso" (KUPFER, 1999b, p. I06). Sobre este último, referente à criança com estrutura psicótica, entende-se que o acesso dela ao seu imaginário pode ter sido interceptado, de modo que "a debilidade da criança atua como uma máscara"; ou seja, encobre a confusão que existe entre os aspectos real e simbólico. Deste modo, a criança psicótica consegue acessar apenas o real, já que o simbólico não pode ser acessado, pois nem mesmo chegou a existir (MANNONI, 1985, p. 28).

Dolto (1985/2013, p. 273), afirma que a criança psicótica possui um desejo narcísico e simbiótico, através do qual busca suprir sua angústia de ser aceita pelo Outro, de modo que ele a aceite da maneira que é; ou seja, "visa, no impossível, incestuosamente, a mãe ou a cena primitiva e transfere-se sobre qualquer outro que aceite o encontro". Tal relação simbiótica com a figura materna se dá, visto que o sujeito busca estabelecer uma relação simbiótica com o Outro, o qual ele deseja, ao mesmo tempo que considera perigoso. $\mathrm{O}$ 
bebê, portanto, tem a fantasia de que tal relação simbiótica é segura para refugiar-se e ter a possibilidade de regredir.

Em um segundo momento, este estudo, procurou esclarecer os manejos clínicos para tratamento da psicose infantil. Quanto a isto, sabe-se que o tratamento de crianças psicóticas na clínica lacaniana utiliza-se da relação da criança com os pais, bem como, da linguagem, das interações que ocorrem, do brincar da criança etc.; ou seja, considera "todo o sentido de SER da criança no mundo" (KLINGER; REIS; SOUZA, 2oII, p. 98). Percebese, deste modo, que a escuta do analista se direciona não só à criança, mas também aos pais, uma vez que a compreensão da dinâmica familiar, da subjetividade e da demanda parental em relação à criança são aspectos fundamentais no processo da psicoterapia de orientação analítica na psicose infantil.

A clínica lacaniana atua no tratamento da psicose infantil com o objetivo de tornar possível ao sujeito refazer a relação de suas marcas simbólicas e significantes com o real. Percebe-se que para tal psicopatologia, é necessário partir do real rumo ao simbólico, já que este ainda não foi instaurado na criança psicótica e, portanto, não se pode pensar em descontruir o que ainda nem chegou a existir. A análise permite, portanto, que este sujeito edifique suas defesas contra o real e construa seus significantes (KUPFER, 1999a).

Além disso, pode-se considerar a psicanálise como um método de prevenção, de modo a cuidar do desenvolvimento das crianças. Segundo Bernardino e Kupfer (2008, p. 678), boa parte das crianças brasileiras, por volta dos três anos de idade, estão com dificuldades para articular suas pulsões às normas de sua cultura. Este fato revela a necessidade dos pais em receberem auxílio para que possam resgatar a função pela qual são responsáveis, isto é, "responsabilizar-se pela transmissão simbólica e promover o surgimento de sujeitos falantes e desejantes”. Compreende-se, assim, que o tratamento psicanalítico pode precaver, de modo a auxiliar os pais a cumprirem sua função e preservarem o desenvolvimento saudável das crianças.

\section{OS CONCEITOS DA PSICOSE NA CORRENTE FRANCESA}

Com o intuito de melhor compreender o diagnóstico diferencial na psicanálise, no que se refere às patologias psicose infantil e autismo, pretende-se neste capítulo apresentar os conceitos da psicose, a partir dos pressupostos teóricos da corrente francesa. Para tal, serão expostos os conceitos de autores renomados como Sigmund Freud, além de Jacques 
Lacan e Françoise Dolto, que dedicaram esforços para pesquisas e compreensões, bem como experiencias clínicas, no que se refere à psicose infantil.

De acordo com Freud, a psicose refere-se a uma defesa do sujeito, o qual sente-se ameaçado e tenta defender sua integridade para preservá-la. Para isolar seu mundo interno da realidade, que está fora e não se trata de uma extensão de si mesmo, ele defende-se e é levado à psicose. Tal ameaça, tem relação com as representações do sujeito sobre o outro, como é o caso de rejeitar aquilo que o outro representa e o sujeito não pode suportar. Para Lacan, o sujeito psicótico defende-se e joga para fora de si mesmo, ou seja, torna foracluído, o significante do Nome-do-Pai. No entanto, apesar das especificidades dos autores, a consequência dessa defesa do sujeito é a mesma: provoca furos simbólicos que correspondem aos furos na realidade (NASIO, 200I).

Sabe-se que, de acordo com a teoria lacaniana, os pais ocupam lugar fundamental na vida do bebê, visto que este encontra-se sujeitado ao desejo de seus pais. Ao longo do desenvolvimento do sujeito, na etapa da primeira infância ocorre a constituição subjetiva do bebê, sendo que cada uma das figuras parentais possui um papel específico (BERNARDINO; VANOLI, 2008).

A figura materna, desde a gestação até os primeiros meses de vida do bebê, contribui com os cuidados integrais. Deste modo, ela se ocupa da função de alienar as pulsões do sujeito ao outro, que neste primeiro momento trata-se da própria figura materna, ou seja, o bebê aliena-se completamente à figura materna. Com isto, desde o nascimento, o bebê compreende que só existem ele e sua mãe. "O objeto real (seio ou mamadeira) trazido pela mãe, no seu desejo de amamentar essa criança, faz com que o que era necessidade (a fome) transforme-se em demanda, demanda de amor”. Esta alienação do bebê à mãe é real e simbólica, sendo imprescindível ao processo de constituição subjetiva, uma vez que possibilita a entrada do sujeito ao campo da linguagem (BERNARDINO; VANOLI, 2008, p. 25I).

Já à figura paterna, cabe a função de inserir o bebê no campo simbólico, ao passo que o bebê se afasta, gradualmente, da alienação e sujeição à figura materna. Quando a figura paterna entra em cena, como sendo significante desta função, é viabilizado ao bebê tornar-se um sujeito desejante. Contudo, caso ocorram falhas neste processo, o significante Nome-do-Pai ficará foracluído, o que representa o processo contrário: o significante que deveria ser inscrito e tornar o bebê um sujeito desejante, é recusado e passa a ficar fora do 
universo simbólico. "A não inscrição da função paterna faz com que não se inscrevam os significantes capazes de funcionar como pontos de basta, como articuladores na cadeia significante necessários à constituição e ao exercício de um sujeito" (BERNARDINO; VANOLI, 2008, p. 25I).

Assim sendo, quando o significante Nome-do-Pai é foracluído, o sujeito situa-se fora da ordem simbólica, sendo a consequência disto a falha da separação entre mãe-bebê, o que propicia a eclosão de uma psicose. Isto se dá, já que a criança permanece alienada, ou seja, impossibilitada de se separar do gozo materno, colocando-se para fora do campo simbólico e metafórico da linguagem (NASIO, 200I).

Lacan (1988), assegura que o significante Nome-do-Pai é indispensável para a constituição simbólica do sujeito. Sabe-se que os significantes, bem como as significações, emergem da rede simbólica e, portanto, a foraclusão do significante Nome-do-Pai resulta em um "furo" na rede simbólica do bebê.

\begin{abstract}
De que se trata quando falo de Verwerfung [foraclusão]? Trata-se da rejeição de um significante primordial em trevas exteriores, significante que faltará desde então nesse nível. [...] Trata-se de um processo primordial de exclusão de um dentro primitivo, que não é o dentro do corpo, mas aquele de um primeiro corpo de significante (LACAN, 1988, p. 171).
\end{abstract}

Sabe-se que todo sujeito, neurótico ou psicótico, entra para o campo na linguagem devido a incompletude do Outro, ou seja, entra para a linguagem já que é impossível dizer tudo. Entretanto, no que se refere ao sujeito psicótico, a partir do momento que esse primeiro e importante significante, Nome-do-Pai, é foracluido, nenhum outro significante poderá representar algo. Com isto, entende-se que o sujeito psicótico se implica no campo da linguagem, embora não consiga fazer uso desta ao ponto que se organize no discurso social (REMIREZ, 2004).

Quanto a isso, Lacan (1998, p. 584), expõe que as alucinações e os delírios se referem à relação específica que o psicótico estabelece com a linguagem, pois "a falta do Nome-doPai nesse lugar que, pelo furo que abre no significado, dá início à cascata de remanejamentos do significante de onde provém o desastre crescente do imaginário, até que seja alcançado o nível em que significante e significado se estabilizam na metáfora delirante”. Alucinações e delírios, portanto, são os modos pelos quais o psicótico equilibra tais significante e significado, defesas necessárias diante da ameaça de aniquilação frente ao real. Isto se dá, já que o furo causado afeta o campo das significações, de modo que alguns significantes que foram excluídos encontram as alucinações como forma de 
retornarem do real. Deste modo, compreende-se que as alucinações são o modo singular do sujeito psicótico de constituir sua relação com a linguagem (BERNARDINO; VANOLI, 2008).

Vale ressaltar que o fato do significante Nome-do-Pai ser foracluído não se refere apenas a relação estabelecida entre a mãe e o pai, mas principalmente, à importância que a mãe dá à palavra do pai, "digamos com clareza, a sua autoridade -, ou, em outras palavras, do lugar que ela reserva ao Nome-do-Pai na promoção da lei”, neste sentido, pode-se dizer que a mãe inclui o pai como figura de corte à alienação bebê-mãe (LACAN, 1998, p. 587).

Enquanto Lacan vê o sujeito psicótico completamente excluído da ordem simbólica, Dolto compreende que além de estar inserida na ordem simbólica, a psicose é causada devido às feridas simbólicas em relação à imagem do corpo, e não ao sujeito. Para a autora, o psicótico não está fora da ordem simbólica, mas perdeu as marcas simbólicas em etapas iniciais e fundamentais do desenvolvimento, devido à ausência de castração simboligênica. Assim sendo, o sujeito se aliena a uma imagem arcaica de seu corpo, fato que o impede de associar seu desejo ao seu corpo, já que ao ser ocultado das marcas simbólicas fica impedido de simbolizar os acontecimentos, o que é traumático ao sujeito (NASIO, 200I).

Compreende-se que Dolto dedicava-se não apenas a aprimorar teorias, mas principalmente em compreender do campo prático para a composição teórica. Considerava que as experiencias clínicas eram fundamentais na redescoberta constante da verdade do sujeito, sendo assim, não se acomodava de maneira sistêmica aos fundamentos teóricos. Da mesma maneira, fomentava aos seus leitores a questionarem sobre as redescobertas, por este motivo, Nasio (200I, p. 164), afirma que "um traço marcante da obra de Dolto é sua capacidade singular de tocar a todos no próprio cerne de sua experiência do inconsciente".

Foi no colóquio sobre psicose infantil organizado por Maud Mannoni, em Paris, 1967, que Françoise Dolto pôde explanar suas hipóteses e até mesmo críticas indiretas no que se refere ao tema. Foi nesta ocasião, a partir do relato das doze sessões que realizou no caso Dominique, adolescente psicótico, que ela afirmou a compreensão de que o papel inconsciente da trama familiar é que contextualiza a psicose. Além disto, contestou, de modo indireto, a visão dos psicanalistas ingleses, que encarregam o sistema social como causa da psicose, e criticou ainda, o estruturalismo inflexível de alguns psicanalistas franceses (NASIO, 200I). 
Para melhor compreender as hipóteses fundadoras de Dolto quanto a psicose infantil, obtidas a partir do caso Dominique, é imprescindível conhecer os conceitos psicanalíticos que sustentam tais hipóteses da autora. Quanto às suas hipóteses, o que sintetiza a origem do ser humano refere-se ao fato de que ele está tanto na ordem da unidade, quanto na ordem da triangulação, isto é, "o ser humano é a encarnação simbólica de três desejos: o do pai, o da mãe e o seu, todos três sendo seres de linguagem." A partir desta concepção, Dolto começou a explorar sobre as questões impensáveis, no que se refere aos primórdios da vida, às feridas narcísicas e ao psicótico (NASIO, 200I, p. I62).

Além disso, Dolto (2013) assegurou que o sujeito é uma unidade primária desde os primórdios de sua vida, ou seja, ele não é constituído de uma desordem inicial, que irá desenvolver-se e tornar-se unidade. Para a autora, ocorre o contrário, o sujeito é um ser de desejo, é unidade desde os primórdios, sendo que, o que se estrutura nas etapas de desenvolvimento a seguir não é o sujeito, mas a sua relação com o desejo.

\footnotetext{
Assim, os momentos-chave da primeira infância que são os estádios devem ser compreendidos como verdadeiras provas iniciáticas: não existe ausência de saber, mas desconhecimento de uma verdade já presente. O que a criança experimenta em seus primeiros anos de vida é uma série de iniciações ao desejo do qual sua própria vida é testemunha. A introdução da ideia de iniciação induz, além disso, a uma referência aos agentes e às regras dessa iniciação: cabe aos pais e aos adultos em geral assumir o encargo iniciático, porquanto eles mesmos foram iniciados na regra fundamental do desejo: a proibição do incesto (NASIO, 20oI, p. 166).
}

Tais hipóteses, contrárias as demais teorias psicanalíticas da época, levaram Dolto a ocupar um lugar único entre os renomados psicanalistas. É importante ressaltar que o objetivo maior de Dolto "foi construir e conceituar uma prática psicanalítica capaz de assimilar o pré-verbal e o pré-especular" (NASIO, 20oI, p. ı62). Tal fato, no entanto, não sugere que Dolto contrapõe-se à loucura, mas reconhece o sujeito psicótico como sendo um sujeito completo, fato que era "precondição e postulado fundadores de sua clínica e de seu sistema teórico" (NASIO, 200I, p. 163), assim como embasava suas hipóteses a partir do "seu enraizamento numa concepção mais global do Sujeito e da ética de seu desejo" (NASIO, 200I, p. 166).

A partir dessas perspectivas, Dolto seguiu com seu maior desafio teórico, que era compreender como o aprisionamento do desejo nas necessidades do corpo do sujeito, e como o inconsciente se estrutura, sendo que está sujeito ao espaço e ao tempo do corpo. Assim, Dolto desvendou este paradoxo a partir do conceito de imagem do corpo, o qual 
também proporcionou a autora a articulação teórica de suas ideias, bem como a legitimação destas no campo da psicanálise (NASIO, 200I).

O desafio teórico de Dolto foi conseguir pensar na ordem do desejo, a despeito de seu aprisionamento nas necessidades do corpo; pensar na ordem do inconsciente, a despeito de sua sujeição ao espaço e ao tempo do próprio corpo. O conceito de imagem do corpo foi fruto da superação desses paradoxos: a imagem do corpo é, a cada instante, o resultado simbólico da experiência atravessada pelo desejo, às voltas com o corpo próprio (NASIO, 200I, p. 166-167).

É importante ressaltar que o esquema do corpo não se trata da imagem do corpo, uma vez que esta é constituída a partir da linguagem e das marcas simbólicas, que se estruturaram a partir da relação com o outro. Deste modo a unidade primária do sujeito, da qual Dolto fala, é representada pela imagem do corpo, visto que esta refere-se a um campo simbólico que possibilita, entre zero e três anos de idade, unificar o sujeito e o seu próprio corpo, ou o emocional e o biológico; isto é, a imagem do corpo possibilita, de modo simbólico, vincular o desejo ao corpo pulsional, caso contrário, conjuga-se um corpo despedaçado (DOLTO, 2013).

Inerente a esse conceito de imagem do corpo, Dolto discorre sobre a castração simboligênica, que se refere às proibições fundamentais proporcionadas inicialmente pelos pais com as quais a criança se depara ao longo de seu desenvolvimento. Estas castrações, necessárias ao desenvolvimento saudável, atuam como restrição do desejo da criança. Tanto esse processo, quanto os efeitos que ele causa na criança, são abordados no conceito da castração simboligênica (NASIO, 20oI).

Compreende-se, portanto, que os conceitos de imagem do corpo e castração simboligênica são concepções teóricas fundamentais para compreensão da psicose infantil, segundo Dolto. Além disto, são conceitos indissociáveis, visto que, a primeira possibilita a dialética entre desejo e corpo próprio, ao mesmo tempo que a segunda propicia a inclusão, nesse jogo dialético, da "sucessão das zonas erógenas, de seus objetos e das manifestações da Lei” (NASIO, 200I, p. I67).

De acordo com Dolto (2013), no que se refere a gênese da psicose, entende-se que esta trata-se da confusão entre a necessidade e o desejo. Tal fato pode estar relacionado à ruptura que ocorre entre a criança psicótica e a mãe, quando esta não consegue estabelecer laços, nem mesmo apropriar-se das necessidades daquela. Com isto, a criança que não fala e não pode levar esta ruptura ao campo da linguagem, acaba mutilando seu corpo de necessidades, sendo que não tem a percepção de onde acaba e seu corpo e começa o do 
outro. Ou seja, a criança não estabelece a dialética entre desejo, a imagem do corpo e as castrações simboligênicas.

Acerca disso, pode-se citar o caso Dominique, no qual nota-se que ao longo de todo o estudo "Dolto manteve um discurso em duas vertentes, no qual os incidentes da imagem do corpo de Dominique encontram eco, a cada etapa, em termos da busca fálica" (NASIO, 2021, p. I68).

No que diz respeito à falta da castração simboligênica, Dolto refere-se à dimensão familiar como sendo uma das origens da psicose, sendo que os pais possuem lacunas em sua própria estrutura do complexo de édipo e por este motivo não são capazes de operar a castração necessária ao seu filho. É neste sentido que Dolto (2013), afirma ser necessário conhecer o Édipo dos pais do paciente, ou seja, conhecer a própria história deles com seus pais, visto que a criança psicótica, aprisionada ao seu desejo arcaico, manifesta-os em códigos a serem decifrados. Para Nasio (200I, p. I68), o psicótico "continua a ser um ser de desejo e de linguagem, que não pode furtar-se totalmente à questão do outro: apesar de tudo, espera um reconhecimento e uma resposta a seu desejo, continua a simbolizar sua falta-a ser".

Em sua clínica, Dolto promove a função imaginária da criança, através do uso de materiais e técnicas lúdicas, como lápis de cor, massa de modelar, realizações plásticas, gestualidade e mímica, já que reiterava que através dos detalhes muito realistas das mediações imaginárias a criança expõe as simbolizações que criou a partir de suas relações humanas. Muitas destas mediações, de fato ocorreram, assim como outras pertencem ao imaginário, todavia, "para a criança, se há desejo, isso é verdade para ela, mas não necessariamente verdade para a pessoa da qual está falando" (DOLTO, 2013, p. 76). É por isto que, segundo Nasio (200I), Dolto assegurava que as tentativas estereotipadas e repetidas de representação da criança psicótica, expressas em tais atividades lúdicas, tratava-se do desejo alienado ao arcaico, do não dito da criança.

Nesse contexto, para Dolto (2013), a relação entre o paciente e o analista proporciona ao analisando a manifestação de seu desejo impensado e arcaico. Isto se dá, pois ao contrário do que ocorreu na história dos pais do paciente psicótico, o analista pôde ser castrado em sua própria história edipiana, sendo assim, a imagem do corpo do analista pode sustentar a transferência, bem como a interpretação da imaginação do paciente. 
lugar das tripas, dos músculos, das sensações ritmadas, das pulsações do sangue, de tudo o que constitui o outro invisível do psicótico (DOLTO, 2013, p. 59).

O analista, no entanto, precisa atentar-se ao ocupar esse lugar, para não dissociar seu próprio narcisismo primário, que emerge neste contexto. Este lugar sustentado pelo analista é, ainda, o espaço que possibilita ao paciente ser castrado e reconstruir a imagem do corpo e "ser aquele graças ao qual ele [paciente] pode chegar a seu próprio desejo (DOLTO, 2013, p. 64).

Percebe-se, pois, que é nesse aspecto que Dolto distancia-se do sistema teórico lacaniano, já que para ela, "o sujeito e a imagem do próprio corpo, o simbólico e as mediações imaginárias, tudo isso está ligado muito antes de o estádio do espelho vir fixar sua estrutura”. Com isto, a psicanalista aflorou o debate sobre o estatuto das mediações imaginárias (NASIO, 200I, p. I86).

\section{MANEJOS CLÍNICOS PARA TRATAMENTO DA PSICOSE INFANTIL}

Nesse capítulo propõe-se analisar as contribuições da história da psicanálise para a clínica infantil, com base nos pressupostos teóricos da psicanálise. Por conseguinte, Lacan sustenta a possibilidade da clínica infantil a partir de sua teoria quanto ao real, imaginário e simbólico, além de afirmar que a transferência ocorre não apenas com o neurótico, mas também com o psicótico. Na mesma linha de pensamento, Mannoni aponta a importância de trabalhar com as crianças, e sobretudo com seus pais, já que aquelas são sintomas destes.

A partir dessa retomada histórica, objetiva-se ainda analisar os manejos psicanalíticos na clínica da psicose infantil. Deste modo, serão abordados temas como o pagamento simbólico, o discurso coletivo - pais, analista, escola e cultura -, a importância da transferência para a criança psicótica aderir ao processo, a decodificação da linguagem e os dispositivos utilizados para acessá-la. Em suma, busca-se apresentar o objetivo da clínica psicanalítica com a criança psicótica, que não se refere à cura dos sintomas apontados pelos pais e sociedade, mas concerne à intenção do analista em auxiliar no alcance e interesse da criança quanto às próprias demandas, em busca de seu bem-estar.

\section{I Contribuições para a clínica psicanalítica infantil}

Diante das experiências clínicas, foi a partir da escuta que Freud pôde demonstrar do que fala o sintoma, isto é, analisou o sentido da fala enigmática, a qual considerava como sendo a única maneira possível de realizar a análise da neurose infantil. Já no que diz 
respeito à pesquisa teórica, o autor interessou-se pelo sentido do sintoma. Ao estudar as histéricas, Freud entendeu que tais traumatismos e lembranças da infância, embora pudessem ser fictícios, obtinham o sentido da fala, que remete à verdade do sujeito, visto que tudo que este diz relaciona-se ao discurso de seu inconsciente, ou seja, de seu desejo (MANNONI, 1999). Sendo assim, desta constatação, entende-se “[...] que o corpo humano é um corpo de sentido, de representações, lugar de metáforas, portanto" (JARDIM, 200I, p. 55).

Além disso, Freud também demonstrou que o sintoma do sujeito é resultado do recalque de uma ideia, que pode aparecer como sintoma físico. Sobre esse funcionamento do aparelho psíquico, entende-se que, “[...] um sintoma tem o estatuto de uma substituição, de uma troca, em que uma ideia a ser escondida é "mostrada" no corpo, cuja produção discursiva produzida sobre o sofrimento do corpo desvelará o que antes fora escondido" (JARDIM, 200I, p. 55-56). Assim, quando essa linguagem do sintoma é descodificada em análise, ou seja, através da fala do sujeito e da escuta do analista, o paciente pode curar-se. Foi com base nessa teoria que Freud falou sobre a cura pela palavra (JARDIM, 200I).

A partir disso, Freud também evidenciou que conduzir as tendências inconscientes do sujeito à consciência é eficaz ao tratamento. Tal descoberta também demonstrou a possibilidade de interpretação na análise de crianças, com base nas considerações do caso do menino Hans. Freud afirmou que o paciente pôde reorganizar seu complexo de édipo, a partir das fantasias de castração. Deste modo, o autor reconheceu a possibilidade de interpretação na análise infantil, a qual passou a ser considerada viável a partir desse momento (MANNONI, 1999).

Ao considerar tais contribuições fundamentais de Freud à psicanálise de crianças, nota-se que ele proporcionou a indispensável percepção quanto ao sentido do sintoma do sujeito, tanto do adulto, quanto da criança. Quando se trata do sentido do sintoma de uma criança, entende-se que ele não se refere ao real, mas ao fato de enfrentar uma série de dificuldades que não foram resolvidas pelos seus pais, visto que os sintomas manifestados pela criança não se referem apenas a ela, mas também aos seus pais (MANNONI, 1999).

Em consonância a isso, pode-se considerar a fundamental contribuição dos pressupostos teóricos de Lacan, que ao diferenciar os termos real, imaginário e simbólico, permitiu melhor adaptação da percepção de Freud sobre o sentido dos sintomas. A 
diferenciação desses termos permite que o tratamento seja conduzido com base no modo como o desejo do sujeito é situado em relação ao Outro (MANNONI, 1999).

Com as crianças, o analista considera o sintoma como sendo em parte verbal, através de sua fala cifrada, e também em parte referente à questão dos pais (MANNONI, 1999). Com isto pode-se evitar incoerências no procedimento da clínica psicanalítica, uma vez que o analista parte do princípio de que:

[...] a análise não é uma relação a dois em que o analista se designa como objeto de transferência. O que importa não é uma situação relacional, mas o que se passa no discurso, ou seja, o lugar de onde o sujeito fala, a quem se dirige e por quem. Qualquer interpretação só pode ser formulada, levando-se em conta o registro em que se encontram analista e analisando. Faltando isto, expomo-nos ao contrasenso (MANNONI, 1999, p. 53).

No que se refere ao sintoma, Mannoni (1999, p. 38) afirma que "o sintoma, como nos mostra Freud, sempre inclui o sujeito e o Outro". Entende-se, pois, que o sujeito disfarça seu desejo e o comunica através de uma linguagem a ser decifrada. Isto ocorre na psicanálise de crianças, que desejam comunicar seu desejo, ao mesmo passo que desejam satisfazer o desejo do Outro, no caso, da sua mãe. Para lidar com tal impasse, a criança cria uma linguagem codificada, a qual expressa por uma "fala enganadora"; assim comunica o que deseja e o satisfaz, mas mantém seu segredo para satisfazer o desejo da mãe (MANNONI, 1999).

De acordo com Nasio (1999), assim como apontou Lacan, há possibilidade de análise com psicóticos, no entanto, tal processo exige planejamento por parte do profissional. Quanto a isto, nota-se que a transferência com psicóticos é possível, visto que eles têm habilidade de e compor realidades distintas e, portanto, podem experimentar a realidade de transferência com o analista, mesmo que em apenas alguns momentos do processo. Isto sinaliza, mais uma vez, a viabilidade de análise com psicóticos, bem como com crianças psicóticas.

Percebe-se que Lacan buscou compreender, em seus estudos, de que modo a linguagem do sujeito implica nas mudanças que ocorrem com ele, e como isto modifica a posição do sujeito frente ao desejo do Outro. Ou seja, Lacan pretende compreender de que modo a linguagem modifica o sujeito, já que entende que em determinado momento não é mais possível obter um pensamento anterior à fala. Para tal, é necessário que o analista se atente não apenas à fala da criança e suas experiências vividas, mas ao fantasma dela, isto é, sua fala perdida. Esta refere-se àquilo que "escapa ao médico" na relação analista- 
paciente, ou seja, as falas cifradas através de sintomas, que são aspectos de maior significado para o sujeito. Quando o paciente comunica em sua linguagem uma fala a ser decifrada pelo analista, ele está "fazendo com isso, em seu sintoma, o significante de um reconhecimento" (MANNONI, I999, p. 49).

\subsection{A clínica psicanalítica da psicose infantil: manejos clínicos}

Para Dolto (2013), os tratamentos das crianças psicóticas precisam ser considerados caso a caso, com suas particularidades. Além disto, deve-se considerar que elas chegam à clínica direcionadas pelos responsáveis e, portanto, não possuem de início sua própria demanda, mas a dos responsáveis. Após algumas sessões e o estabelecimento da transferência com o analista, a criança psicótica consegue colocar os pais para fora e ter sua própria sessão analítica, bem como sua própria demanda. Embora ela não fale e não possua noção de tempo, após a transferência estabelecida, o analista esclarece sobre os dias e horários das sessões e a criança consegue organizar-se internamente a ponto de saber tais informações e esperar, semanalmente, o encontro com o analista.

É por esse motivo que Dolto (2013) considera que as crianças psicóticas também possuem pagamento simbólico e são "inteligência pura”, termo que ela utiliza para referirse ao fato de que tais crianças são iguais a qualquer ser humano; ou seja, possuem função simbólica. Entretanto, elas não possuem meios para torná-la perceptível aos demais. Tratase de um esquema de organização interna com códigos que não são facilmente decifrados. Entretanto, é inquestionável que a criança psicótica entende e se comunica, mesmo que seja a partir de características idiossincráticas. A codificação indecifrável se dá pela ausência da castração na criança psicótica, e a função do analista refere-se justamente em decifrar tais códigos, de acordo com as particularidades da criança e a relação com suas experiências de vida.

\footnotetext{
A inteligência é função simbólica, e todo ser humano a tem. Mas, como não há representação possível sem um código, essa função simbólica não pode abrir mão de meios, ou seja, das mediações que a percepção e a castração representam. Aceitar uma codificação é aceitar uma castração: é reconhecer que, para poder exprimir suas próprias percepções e receber as do outro, é necessário passar por um código comum (DOLTO, 2013, p. 27I).
}

Nota-se que um aspecto imprescindível para iniciar a análise é que haja concordância da criança antes de iniciar o processo, ou seja, aguardar o estabelecimento de transferência, informá-la sobre as sessões e, a partir disso, compreender se ela está disposta 
a realizar o tratamento e qual angústia a própria criança deseja entender. $O$ analista investiga qual a demanda em questão, que causa sofrimento no paciente e o deixa infeliz, pois sabe-se que a angústia que a criança quer entender, na maioria das vezes, não é a mesma angústia que os pais desejam que ela trabalhe na análise (DOLTO, 2013). A partir disso, compreende-se que a transferência estabelecida entre a criança e o analista "pode fazer emergir sentimentos hostis ou afetuosos e pode ser um importante instrumento na autonomia e inclusão de uma criança com necessidades especiais" (ARAÚJO; FIAMENGHI-JR, 2021, p. 52).

Estabelecer a transferência com a criança psicótica trata-se também de cuidar do primeiro impasse da estrutura psicótica, no qual o analista ocupa lugar de sujeito enquanto a demanda do outro ocupa o lugar de objeto. $\mathrm{O}$ esperado para estabelecer-se a análise seria ocorrer o contrário, por isso, o ponto de partida do analista com a criança psicótica é consolidar a transferência, que resulta na inversão do lugar que o analista ocupa na cena analítica, isto é, passa a encarregar-se do lugar de objeto (KUPFER, 1996).

A partir do momento no qual a transferência permite a inversão esperada de tais papeis e a criança concorda com o processo, o analista precisa atentar-se a outra adversidade da estrutura psicótica: a dificuldade do analista em compreender o que se passa na cena analítica, devido à ausência da fala da criança psicótica. Para defrontar essa situação, é fundamental o uso de diferentes dispositivos para que a linguagem do paciente se instale. Sabe-se que faz parte da análise infantil o uso de objetos mediadores, para que a criança se expresse por diversas vias. Com a criança psicótica, pois, tal uso é indispensável para que o analista alcance seu objetivo de "instalar o discurso analítico, no qual o analista ocupa de modo "semblante" o lugar de objeto a para seu analisante" (KUPFER, 1996, p. 19).

Em consonância a isso, Nasio (200I) aponta que o uso desses dispositivos na análise de crianças psicóticas foi defendido por Dolto, a qual percebeu, com base na análise de Dominique, que a função imaginária da criança se manifestava nas produções dos atendimentos e apresentavam aspectos do psiquismo. Para a psicanalista, o uso de materiais como desenhos e realizações plásticas referem-se às projeções do paciente quanto à imagem do corpo, sendo que estes materiais poderiam ser interpretados pela analista devido ao espaço de transferência instalado na cena analítica.

Dolto afirmava que o que a criança desenha ou modela numa sessão é sua imagem do corpo atualizada na transferência. Essa é uma proposição que ultrapassa amplamente a simples análise simbólica das realizações plásticas da 
criança na sessão, uma vez que as torna indissociáveis do próprio processo analítico. Em sua obra, Françoise Dolto deixou-nos inúmeros exemplos da maneira como se apoiava nas produções da criança no estabelecimento da transferência e em suas interpretações (NASIO, 200I, p. 170).

É por esse motivo que, de acordo com a instituição Lugar de vida, o processo analítico de crianças psicóticas necessita ir além do enquadre analítico clássico da psicanálise, e experimentar variações técnicas para o avanço do tratamento. São os casos de uso de desenhos, fantoches, argila, jogos etc., os quais tem o propósito de articular o mundo interno da criança com o mundo externo, do mesmo modo que ocorre com os significantes quando são expressos através da fala (KUPFER, 1996). Quanto a isto, Nasio (200I, p. 171-172) aponta que a psicanalista Dolto afirmava que "a análise devia permitir o retorno das imagens carentes de castração simboligênica: em outras palavras, a análise é um tempo e um espaço de manifestação da regressão que dão uma nova oportunidade de encontrar as castrações”.

Assim, a fim de consolidar a análise de crianças, é fundamental atentar-se também ao discurso e ao inconsciente dos pais do paciente, já que o discurso psicanalítico nos remete aos desejos. Deste modo, na psicanálise com crianças considera-se que o discurso destas trata-se de um discurso coletivo, que remete não apenas ao mundo interno da criança, mas também ao mundo fantasmático dos pais. Este se manifesta nos sintomas da criança, uma vez que ela "é o suporte daquilo que os pais não podem enfrentar" (MANNONI, 1999, p. 14).

Além disso, também faz parte do discurso coletivo da criança o próprio analista, que através dos processos de transferência e contratransferência, defesas e angústias inconscientes, passa a ser "[...] confrontado a sua própria representação da infância e o peso de suas motivações inconscientes se refletirá na orientação dada ao tratamento" (MANNONI, 1999, p. I8). Deste modo faz-se necessário que o analista se atente às contratransferências e entenda o modo como se envolve na relação de transferência, a fim de conseguir diferenciar quais questões se referem ao seu conteúdo interno e quais são do paciente (ARAÚJO; FIAMENGHI-JR, 2021, p. 53).

Sobre os impasses nos manejos clínicos, é imprescindível considerar não apenas a contribuição dos pais e do analista no discurso coletivo da criança psicótica, mas também o pilar da educação, que necessita estar em consonância com o tratamento analítico (KUPFER, 1996). Quanto a este aspecto, pode-se considerar que é necessário o apoio da instituição escolar para a inclusão da criança, de modo que "seus integrantes compreendam 
a criança não só como alguém acometido por um diagnóstico, mas considerando seus elementos psicológicos, sociais e não ignorando o seu potencial de constituir-se como um sujeito autônomo" (ARAÚJO; FIAMENGHI-JR, 2021, p. 53).

Uma crise psicótica desencadeada na infância ou na adolescência, por se tratar de um momento ainda imaturo do desenvolvimento, muito provavelmente resultará em desordens consideráveis no desenvolvimento do sujeito. Para Kupfer (1996, p. 23), "a criança que se apresenta a nós não é apenas um sujeito em meio a uma crise, é também uma pessoa correndo o risco de não crescer nunca mais”. A eclosão precoce significa que a psicose se estabelece antes da criança começar a falar, de modo que ainda não criou muitos de seus próprios significantes, o que fará desse sujeito muito diferente de um psicótico adulto, que teve esse desenvolvimento. Assim sendo, é fundamental que essa criança entre em contato com o mundo escolar e cultural, para evitar que, em sua idade adulta, não sofra também de debilidade mental. Se isto acontece, embora busque tratamento analítico, terá chances reduzidas de sua recuperação social (KUPFER, 1996).

Com isso, compreende-se que de modo algum a análise com crianças psicóticas tem o objetivo de "curá-la de um sintoma do qual a sociedade ou os pais gostariam de vê-la livre" (DOLTO, 2013, p. 271). Entende-se, portanto, que a teoria lacaniana acerca do inconsciente aponta que é possível realizar tratamentos com sujeitos psicóticos, todavia, existem limites para a condução do tratamento, já que o objetivo da psicanálise não é de curá-los (JARDIM, 200I).

É importante pensar que, os pais, ao notarem dificuldades no desenvolvimento da criança, passam a tutelar as ações dela, como se seus corpos fossem continuação do corpo da criança. Cabe ao analista explicar a eles que é fundamental para o tratamento que a criança comece a satisfazer suas necessidades com o próprio corpo, seja alimentar-se, limpar-se ou alcançar um brinquedo com as próprias mãos (DOLTO, 2013).

\begin{abstract}
Senão nem adianta começar um tratamento: vocês, psicanalistas, não saberão, em tais condições, quem estarão tratando, já que estarão lidando com um corpo que continua em um outro corpo; ou seja, com um sujeito que não é castrado, com pais que tampouco o são. A criança é, então, uma parte do corpo deles, do desejo deles. Não colocaram entre eles próprios e ela a mediação dessa parte distinta do corpo da criança: a mão, que, nos seres humanos, serve para fazer aquilo que é necessário à satisfação das necessidades (DOLTO, 2012, p. 213).
\end{abstract}

Os pais tendem a ocupar-se desse lugar de extensão do corpo do filho psicótico, visto que tampouco eles mesmos passaram pela castração e, sendo assim, projetam seus desejos e necessidades na criança, de modo que a família age como se fossem uma extensão 
do corpo do outro. Essa satisfação de necessidades do corpo da criança precisa ser modificada e, para tal, a compreensão e auxílio dos pais é fundamental ao processo analítico. Sabe-se que eles "não têm necessidade de que o corpo do filho esteja colado ao deles, como um parasita. O comportamento corporal deles, seus carinhos, gestos, sua ajuda material devem ser linguagem de amor e expressão de uma relação tutelar" (DOLTO, 2013, p. 273).

Os pais necessitam, pois, ser ativos no tratamento, bem como estar cientes de tudo que ocorre na análise, até o momento em que ocorra a separação entre eles e a criança. Esta deve ser informada pelo analista, que após tal separação, ela estará apta a agir por si só e satisfazer suas necessidades, dentro e fora na análise (DOLTO, 2013).

Quanto a contribuição do analista ao processo, vale também ressaltar que a teoria é importante para que ele esteja inteirado quanto à psicose, contudo, os obstáculos desta geram conflitos com os limites do método. Isso se dá já que cada sujeito possui suas experiências de vida que são únicas e, portanto, a manifestação da psicose modifica-se em cada caso, assim como transforma-se no mesmo sujeito com o passar dos anos (JERUSALINSKY, 2010).

Qualquer tentativa de uniformizar a leitura, ou de fazer uma nosografia ou uma taxonomia para uniformizar a leitura, nos levaria ao fracasso da compreensão da psicose. Podemos, por métodos bioquímicos e neuroquímicos, reduzir a expressão sintomática, mas certamente não conseguiríamos que o fantasma se desligasse do corpo, que é a cura que podemos tentar (JERUSALINSKY, 2010, p. 17-18).

Nota-se, que para a psicanálise é fundamental atentar-se não apenas à teoria, mas à história de cada sujeito, uma vez que a psicanálise trata-se do "cancelamento do método". Tal fato não significa desconsiderar a teoria, mas dar abertura para que o analista faça, a partir da transferência, sua própria compreensão de cada caso e, ao integrar sua bagagem teórica e análise subjetiva do caso do paciente, decida o melhor caminho a seguir no tratamento (JERUSALINSKY, 2010, p. 17-18).

Segundo Kupfer (1996, p. 28), “por todas essas razões, não tem sido fácil analisar psicóticos - e menos ainda as crianças autistas e psicóticas”. Todavia, é substancial enfatizar que diversas instituições de orientação psicanalítica, a fim de ascender quanto às dificuldades, iniciaram experiências de transformação do método clássico para alcançar o discurso analítico, e encontraram eficácia no tratamento de crianças psicóticas, à luz da psicanálise. 


\section{DISCUSSÃO}

A partir do diagnóstico diferencial entre autismo e psicose infantil, este trabalho propôs investigar sobre os conceitos da psicose infantil e os manejos clínicos para tratamento desta, a partir da perspectiva da escola francesa. Foi possível analisar alguns aspectos, discutidos a seguir.

Para a psicanálise, o psicótico está no campo da linguagem, mas fora do discurso. Deste modo, Freud diz que a psicose é o modo do sujeito defender e preservar seu mundo interno das ameaças da realidade (NASIO, 20oI). Neste sentido, Lacan aponta que para tal defesa o psicótico terá o significante Nome-do-Pai foracluído. Isso se dá, já que no início do desenvolvimento, o bebê é sujeitado aos pais e depende das funções de cada um deles, sendo a função da figura materna proporcionar cuidados integrais, e a da figura paterna romper a alienação de sujeição do bebê à figura materna, de modo a inseri-lo no campo simbólico. Contudo, se a mãe não inclui o pai no corte da alienação entre ela e o bebê, há falha no processo, o significante Nome-do-Pai é foracluído e o sujeito passa a situar-se fora da ordem simbólica, visto que outros significantes não podem ser inscritos. Esta falha de desenvolvimento pode propiciar a eclosão da psicose na infância (BERNARDINO; VANOLI, 2008).

Entretanto, enquanto Lacan vê o sujeito psicótico completamente excluído da ordem simbólica, Dolto aponta que a psicose está inserida na ordem simbólica, mas é causada devido às feridas simbólicas em relação à imagem do corpo, e não ao sujeito. Para a autora, a psicose infantil é compreendida a partir dos aspectos de unidade, triangulação, primórdios da vida e feridas narcísicas, sendo que a gênese da psicose pode relacionar-se às falhas de desenvolvimento nos conceitos indissociáveis de imagem do corpo e castração simboligênica (NASIO, 200I).

A imagem do corpo refere-se ao vínculo simbólico entre o desejo e o corpo pulsional, já a castração simboligênica refere-se às castrações proporcionadas pelas figuras dos pais no início do desenvolvimento, que atuam como restrição e manifestação da Lei em relação ao desejo da criança. Deste modo, Dolto afirma que a gênese da psicose trata-se da confusão entre a necessidade e o desejo do sujeito, sendo que a ruptura de laços entre o bebê e a mãe pode levar a uma ruptura do bebê no campo da linguagem, referente a falha da imagem do corpo. Além disso, as influências da trama familiar, bem como de conflitos 
nas estruturas de complexo de édipo das figuras parentais, referem-se a falha na castração simboligênica (NASIO, 200I).

A partir desses pressupostos teóricos, com a análise das contribuições para a clínica psicanalítica infantil, nota-se a importância do legado de Freud sobre a fala para a cura, a partir da escuta do psicanalista, que busca aproximar-se do sentido do sintoma, bem como decodificar a linguagem. Freud mostra ainda a possibilidade de análise com crianças. $\mathrm{Na}$ mesma linha de pensamento, Lacan sustenta a possibilidade da clínica infantil com base em sua teoria sobre: real, imaginário e simbólico, além de afirmar que a transferência é possível no sujeito psicótico. Deste modo, Mannoni ressalta a importância de trabalhar com as crianças, e sobretudo com seus pais, já que aquelas são sintomas destes (MANNONI, 1999).

Essa retomada histórica possibilitou compreender os manejos clínicos utilizados na clínica da psicose. Sabe-se que todas as crianças possuem função simbólica desde a vida fetal. As crianças psicóticas, no entanto, não conseguem tornar sua função simbólica perceptível aos demais, tornando sua comunicação mais complicada (DOLTO, 2013).

A transferência é condição indispensável no processo, visto que é fator fundamental para que a criança psicótica possa aderir ao tratamento, entrar em contato com o mundo interno e apresentar suas demandas (DOLTO, 2013). A transferência também possibilita o acesso da criança aos sentimentos e desenvolvimento da autonomia (ARAÚJO; FIAMENGHI-JR, 202I).

No que se refere aos dispositivos utilizados para o tratamento, pode-se citar que desenhos, fantoches, argila, jogos etc., objetivam articular os mundos interno e externo, de modo a acessar e decodificar a linguagem da criança, assim como ocorre no neurótico, através da fala e atos falhos (KUPFER, 1996).

Nota-se que é imprescindível considerar não apenas o mundo interno da criança psicótica, mas também o discurso coletivo, isto é, o mundo fantasmático dos pais, defesas e angústias inconscientes do próprio analista, além dos contextos escolar e cultural que rodeiam a criança. É fundamental, pois, a participação ativa desta coletividade no processo do tratamento (MANNONI, 1999).

O objetivo da clínica lacaniana com a criança psicótica, portanto, não é curá-la, mas compreender a demanda e sofrimento desta e a auxiliar na busca de bem-estar. Assim sendo, foi possível perceber que há eficácia no tratamento de crianças psicóticas, a partir 
do método de tratamento psicanalítico, contudo, ainda se sabe pouco sobre as definições precisas da patologia e são necessárias mais pesquisas sobre o tema (KUPFER, 1996).

\section{CONSIDERAÇÕES FINAIS}

Com base no problema de pesquisa, que buscou analisar de que maneira a clínica lacaniana pode contribuir para o tratamento na psicose infantil, foi possível identificar que para a psicanálise há o diagnóstico diferencial entre a psicose infantil e o autismo. Para tal, foram realizadas leituras clássicas de psicanalistas fundamentais como Sigmund Freud, Jacques Lacan, Françoise Dolto e Maud Mannoni, além de buscar a contribuição de psicanalistas contemporâneos envolvidos constantemente na temática, como Maria Cristina Machado Kupfer e Alfredo Jerusalinsky.

Desse modo, foi possível notar, quanto às contribuições para a clínica infantil, que a psicanálise tem como objetivo contribuir na compreensão da demanda da própria criança em sofrimento, de modo a auxiliá-la em seu desenvolvimento e qualidade de vida. Assim também ocorre com o tratamento da psicose infantil, no qual, os autores apontam como principal objetivo o auxílio do analista no processo da criança em refazer a relação com suas marcas simbólicas e de seus significantes com o real.

A partir disso, foi possível perceber que o tratamento da psicose infantil de viés psicanalítico, portanto, não busca a cura para tal diagnóstico, pois compreende como uma maneira de ser frente a linguagem. Assim sendo, a pesquisa buscou compreender os manejos utilizados para tal e foram identificados alguns dos recursos utilizados no processo analítico, como: a condição indispensável da transferência entre analista e paciente; a participação imprescindível do discurso coletivo da criança, isto é, o trabalho em conjunto com os pais e a escola e o uso de dispositivos mediadores, no setting analítico, para facilitar o acesso ao mundo interno da criança.

A análise do trabalho evidencia que há eficácia no tratamento de crianças psicóticas, à luz da psicanálise, com base nas experiências de transformação do método clássico, com objetivo de alcançar o discurso analítico. Todavia, nota-se que ainda há limitações neste estudo e faz-se necessário aumento de pesquisas sobre o tema, visto que se sabe pouco sobre as definições precisas da psicose infantil. Ressalta-se que novas pesquisas são fundamentais para que a clínica psicanalítica desenvolva ainda mais seus métodos e tratamentos. 


\section{REFERÊNCIAS}

ARAÚJO, Gustavo Porfírio; FIAMENGHI-JR, Geraldo Antônio. Transference between a Child with Cerebral Palsy and His Mediator: Applied Psychoanalysis in School Settings. Hmlyn J Human Cul Stud; Vol-2, Iss-3, p. 49-53, 202I. Disponível em: https://himjournals.com/article/articleID=223 Acesso em: 29 set. 2021.

BERNARDINO, Leda Mariza Fischer; KUPFER, Maria Cristina Machado. A criança como mestre do gozo da família atual: desdobramentos da "pesquisa de indicadores clínicos de risco para o desenvolvimento infantil”. Revista Subjetividades, v. 8, n. 3, p. 66I680 , 2008.

Disponível

em:

http://pepsic.bvsalud.org/scielo.php?script=sci_arttext\&pid=SI518-61482008000300005

Acesso em: 5 mar. 202I.

BERNARDINO, Leda Mariza Fischer; VANOLI, Enriqueta Nin. Psicose infantil - uma reflexão sobre a relevância da intervenção psicanalítica. Estilos da Clínica, v. 8, n. 25, p. 250-267, 2008. Disponível em: https://www.revistas.usp.br/estic/article/view/46042 Acesso em: 29 set. 202I.

COELHO, Daniel Menezes; SANTOS, Marcus Vinicius Oliveira. Apontamentos sobre o método na pesquisa psicanalítica. Analytica, São João del Rei, v. I, n. I, p. 90-105, 2012. Disponível em: http://pepsic.bvsalud.org/scielo.php?script=sci_arttext\&pid=S23165197201200o100oo6\&lng=pt\&nrm=iso Acesso em: 13 abr. 2021.

CORREIO, Isabelle Cerqueira Sousa; CORREIO, Flávia Brandão Araújo Pinheiro; CORREIO, Elenise Tenório de Medeiros Machado. A relevância da psicoeducação familiar e o papel da família na reabilitação neuropsicológica do TEA. Brazilian Journal of Development, v. 7, n. 3, p. 22558-22570, 2021. Disponível em: https://www.brazilianjournals.com/index.php/BRJD/article/view/2583I Acesso em: 5 mar. 202I.

DOLTO, Françoise. (1985) Seminário de psicanálise de crianças. São Paulo: Martins Fontes, 2013.

JARDIM, Gislene. Psicoses e autismo na infância: impasses na constituição do sujeito. Estilos da Clínica, [S. 1.], v. 6, n. Io, p. 52-68, 2001. DOI: 10.11606/issn.1981-1624.v6irop52-68. Disponível em: https://www.revistas.usp.br/estic/article/view/6roz8 Acesso em: 22 abr. 2021. 
JERUSALINSKY, Alfredo. As quatro estruturas fundamentais do sujeito: autismos, psicoses, neuroses e perversões. Revista da Associação Psicanalítica de Porto Alegre, Porto Alegre, n. $38, \quad$ p. 9-19, 2010. Disponível em: https://appoa.org.br/uploads/arquivos/revistas/revista38-I.pdf\#page=7 Acesso em: 26 mai. 202I.

KUPFER, Maria Cristina Machado. A presença da psicanálise nos dispositivos institucionais de tratamento da psicose. Estilos da clínica, v. I, n. I, p. 18-33, 1996. Disponível em: http://pepsic.bvsalud.org/scielo.php?script=sci_arttext\&pid=SI4I5712819960ooroooo3 Acesso em: 30 mai. 2021.

KUPFER, Maria Cristina Machado. Psicose e autismo na infância: problemas diagnósticos. Estilos da Clínica, [S. 1.], v. 4, n. 7, p. 96-107, I999b. DOI: 10.11606/issn.1981I624.v4i7p96-ı7. Disponível em: https://www.revistas.usp.br/estic/article/view/6o771 Acesso em: 5 mar. 2021.

KUPFER, Maria Cristina Machado. Freud e a educação, dez anos depois. Revista da Associação Psicanalítica de Porto Alegre, v. 9, n. 16, p. 14-25, 1999a. Disponível em: http://www3.fe.usp.br/secoes/inst/novo/acervo_lajonquiere/PDF_SWF/279.pdf\#page=13 Acesso em: 5 mar. 2021.

KLINGER, Ellen Fernanda; REIS, Beatriz Kauri dos; SOUZA, Ana Paula Ramos de. A inclusão dos pais na clínica das psicoses infantis. Estilos da Clínica, São Paulo, v. I6, n. I, p. 96-II5, jun. 20Ir. Disponível em: https://www.revistas.usp.br/estic/article/view/46ro9 Acesso em: 5 mar. 202I.

LACAN, Jacques. O Seminário, livro 3, As Psicoses (1955-1956). Rio de Janeiro, Jorge Zahar, 2.ed. rev., 1988.

LACAN, Jacques. De uma questão preliminar a todo tratamento possível da psicose (p. 584). In: Escritos I (1901-1981). Tradução: Vera Ribeiro. Rio de Janeiro: Jorge Zahar Ed., 1998.

MANNONI, Maud. A insuficiência mental - crianças de estrutura psicótica (p. 27-30) In: A criança retardada e a mãe. São Paulo: Martins Fontes, 1985.

MANNONI, Maud. A Criança, sua "Doença", e os Outros. São Paulo: Via Lettera Editora e Livraria, I999. 
NASIO, Juan David. Como trabalha um psicanalista? Rio de Janeiro: Jorge Zahar Ed., 1999.

NASIO, Juan David. Os grandes casos de psicose. Rio de Janeiro: Jorge Zahar Ed., 2001.

RAMIREZ, Heloísa Helena Aragão. Sobre a metáfora paterna e a foraclusão do nome-dopai: uma introdução. Mental - ano II, n. 3, p. 89-Io5, Barbacena, 2004. Disponível em: http://pepsic.bvsalud.org/pdf/mental/v2n3/v2n3ao8.pdf Acesso em: 29 set. 202I. 